\title{
(9) (1) \\ ESTRADAS VISSUNGUEIRAS NA CENA \\ CONTEMPORÂNEA: ORIGEM E DESENVOLVIMENTO DA PLATAFORMA GARIMPAR EM MINAS NEGRAS CANTOS DE DIAMANTE
}

\author{
Luciano Mendes de Jesus ${ }^{1}$
}

Resumo: Este artigo apresenta uma síntese do desenvolvimento da plataforma de pesquisa e criação artística Garimpar em Minas Negras Cantos de Diamante em torno da investigação das relações criativas entre cultura negra tradicional e artes cênicas contemporâneas, através de estudos práticos e teóricos sobre os elementos performativos e sonoro-musicais presentes nos vissungos, cantos afro-brasileiros de ocorrência no norte de Minas Gerais, na região do Alto Jequitinhonha.

Palavras-chave: Teatro. Música. Cultura afro-brasileira. Tradição. Contemporaneidade.

\section{VISSUNGUEIRAS ROADS IN THE CONTEMPORARY SCENE: ORIGIN AND DEVELOPMENT OF THE PLATAFORMA GARIMPAR EM MINAS NEGRAS CANTOS DE DIAMANTE}

Abstract: This article presents a synthesis of the development of the research platform and artistic creation Garimpar em Minas Negras Cantos de Diamante around the investigation of the creative relations between traditional black culture and contemporary scenic arts, through practical and theoretical studies on the performative and sonorous-musical elements present in the vissungos, Afro-Brazilian songs of occurrence in the north of Minas Gerais, in the region of Alto Jequitinhonha.

Keywords: Theater. Music. Afro-Brazilian culture. Tradition. Contemporaneity.

\section{ROUTES VISSUNGUEIRAS DANS LA SCÈNE CONTEMPORAINE: ORIGINE ET DÉVELOPPEMENT DE LA PLATAFORMA GARIMPAR EM MINAS NEGRAS CANTOS DE DIAMANTE}

Resumé: Cet article présente une synthèse du développement de la plateforme de recherche et de la création artistique Garimpar em Minas Negras Cantos de Diamante autour de la recherche des relations créatives entre la culture noire traditionnelle et les arts de la scène contemporains, à travers des études pratiques et théoriques sur éléments performatifs et sonore-musicaux présente

\footnotetext{
${ }^{1}$ Luciano Mendes de Jesus atua na interface entre teatro e música. É também professor e pesquisador, bacharel em Artes Cênicas (UNICAMP), técnico em Percussão Popular (EMESP), mestre em Música e doutorando em Artes Cênicas (USP). Colaborou com o Workcenter of Jerzy Grotowski and Thomas Richards (Itália/2012 - 2015). Coordena a ação artística Ponte Elemento Per desenvolvendo atualmente a Plataforma Garimpar em Minas Negras Cantos de Diamante, explorando as relações entre os vissungos (cantos de origem Bantu ocorridos no interior de Minas Gerais) e a criação teatral contemporânea. E-mail: mridangan@yahoo.com.br
} afro diaspóricas • julho de 2019, p.45-72 
dans les vissungos, chansons afro-brésiliennes d'occurrence au nord de Minas Gerais, dans la région de Alto Jequitinhonha.

Mots-clés: Théâtre. Musique. Culture afro-brésilienne. Tradition. Contemporanéité

\author{
CAMINOS VISSUNGUEIROS EN LA ESCENA CONTEMPORÁNEA: \\ ORIGEN Y DESARROLLO DE LA PLATAFORMA GARIMPAR EM MINAS \\ NEGRAS CANTOS DE DIAMANTE NEGRAS
}

Resumen: Este artículo presenta una síntesis del desarrollo de la plataforma de investigación y creación artística Garimpar em Minas Negras Cantos de Diamante en torno a la investigación de las relaciones creativas entre cultura negra tradicional y artes escénicas contemporáneas a través de estudios prácticos y teóricos sobre los elementos performativos y sonoro-musicales presentes en los vissungos, cantos afro-brasileños de ocurrencia em en el norte de Minas Gerais, en la región del Alto Jequitinhonha.

Palabras clave: Teatro. Música. Cultura afro-brasileña. Tradición. Contemporaneidad.

\title{
VISÕES E ESCUTAS PANORÂMICAS
}

A Plataforma Garimpar em Minas Negras Cantos de Diamante propõe a investigação das relações entre cultura tradicional e artes cênicas contemporâneas, através de estudos etnosonográficos e criações etnoficcionais sobre elementos performativos, dramatúrgicos e musicais presentes e passíveis de serem extraídos dos cantares africanos e afro-diaspóricos.

Para que se possa compreender o percurso de desenvolvimento desta ação artística devemos observar, ainda que panoramicamente, os elementos que desde o início o alicerçam, sendo estes: os cantos afro-mineiros de tradição Bantu, os vissungos, e os fundamentos operativos do trabalho performativo baseado em tecnologias das tradições, desenvolvido pelo Workcenter of Jerzy Grotowski and Thomas Richards.

Então a partir deste terreno assegurado pelas referências culturais e conceituais que sustentam este projeto artístico será possível entender o seu sentido, formado por uma práxis e um ethos apoiados em perspectivas epistemológicas afro-diaspóricas e em diálogo com pressupostos das atuais discussões da cena contemporânea.

Inicialmente chamada genericamente de "projeto" até recentemente, quando passamos a concebê-la como um amplo suporte para diferentes naturezas de projetos artístico-culturais em torno de um mesmo eixo temático, a Plataforma Garimpar... 
principiou o seu desenvolvimento em 2014, a partir da elaboração escrita das primeiras ideias, para a busca de possíveis patrocinadores através de editais e afins.

Em 2016 começou sua fase de campo, tendo já o suporte da Bolsa Funarte de Fomento para Artistas e Produtores Negros, concedida quando ainda havia o MinC (Ministério da Cultura) com ações afirmativas e descentralizadas, antes da atual subordinação como Secretaria de Cultura, sub-pasta do Ministério da Cidadania, outra ação de retrocesso do atual governo brasileiro.

Ao ocuparem um lugar central dentro das nossas propostas de pesquisa e criação teatral, os vissungos passam a ser ferramentas para a construção de diálogos transatlânticos atemporais e críticos com os agenciamentos míticos, históricos e utópicos de uma África com a qual estamos radicalmente ligados. Desenvolvemos artisticamente uma nova forma de "conversa ritualizada"2 (Lienhard, 1998, p. 142), na qual o entendimento das heranças da diáspora e ao mesmo tempo as diferenças culturais entre Brasil e África se dão através do ato de cantar.

O projeto, dentro de um desenvolvimento orgânico em suas diferentes etapas, ou seja, sem grandes lapsos temporais entre as mesmas, realizou uma série de ações formativas e intercâmbios concomitantemente à criação dos espetáculos da "Trilogia Vissungueira". Tudo isto ao longo de cinco anos (2014 - 2019). E ainda em curso.

Houve pesquisas de campo e buscas audiovisuais e bibliográficas acerca dos vissungos em todas as três fases da plataforma até o momento. Cada fase, focada na criação de um espetáculo, mas articulada com outras ações demandadas pela plataforma (como workshops, palestras, intercâmbios, mesas de debates), apresentou ao final uma obra cênico-musical, sendo estas: Episódio I: Uenda-congembo (morrer), Episódio II: Mileke entre Pedras e Piercings e Episódio III: Banzo e os Filhos dos Antigos, apresentadas em São Paulo, Rio de Janeiro e Minas Gerais.

Sobre estas produções e outras ações geradas a partir da Plataforma Garimpar... falaremos no decorrer deste artigo.

\footnotetext{
${ }^{2}$ A noção de conversa ritualizada é proposta pelo antropólogo Martin Lienhard e identifica a função do canto ritual em cultos afro-americanos como uma forma de se criar um diálogo ativo com a ancestralidade e a terra africanas, de forma a atualizar estas presenças como memória e experiência física reminiscente.
} 
A base técnica que sustenta este projeto artístico, no que concerne ao modo de abordagem dos cantos em relação à atuação, é advinda do período de atuação como performer no Workcenter of Jerzy Grotowski and Thomas Richards, dentro da equipe do Open Program.

O Workcenter of Jerzy Grotowski and Thomas Richards foi fundado em 1986 a convite da Fondazione Pontedera Teatro, na cidade de Pontedera, província de Pisa, região da Toscana, Itália. É um centro internacional de pesquisa em artes performativas que já recebeu artistas e pesquisadores dos cinco continentes. Neste local Grotowski (1933 - 1999), encenador e pesquisador polonês, divisor de águas na história do teatro contemporâneo, realizou suas últimas investigações.

Thomas Richards, afro-estadunidense cuja família tem raízes jamaicanas ${ }^{3}$, foi seu principal colaborador desse período e tornou-se herdeiro da sua obra, com a responsabilidade de avançar nas pesquisas empreendidas. É o atual diretor artístico da instituição.

A pesquisa central da instituição é nomeada "Arte como Veículo", e tem como busca estudar os aspectos interiores e verticais da performatividade, o trabalho que o performer empreende "sobre si mesmo" psicofisicamente.

A ferramenta principal para esse trabalho são os cantos de tradição (ou cantos vibratórios) afro-caribenhos (Haiti e Cuba) e a criação de estruturas de ações físicas fundamentadas em comportamentos orgânicos na atuação. Na fase inicial do Workcenter (1986 a 1999), assim como já vinha sendo realizado desde 1972 por Grotowski, não são criados espetáculos públicos ou obras teatrais na acepção comum do termo. O elemento performativo é estudado como meio de criação de estados expandidos de consciência, entre atuantes e "testemunhas" (nome dado para uma qualidade específica de espectadores que eram convidados a assistir as ações performativas ainda fechadas ao grande público nesse período).

\footnotetext{
${ }^{3}$ Seu pai, Lloyd Richards (1919-2006), foi um dos primeiros artistas negros bem-sucedidos na Broadway, além de realizar, posteriormente, sólida carreira acadêmica na Universidade de Yale, onde chegou a ser reitor da Yale School of Drama e professor emérito.
}

Revista da ABPN • v. 11, Ed. Especial - Caderno Temático: Cultura popular em cena: artes afro diaspóricas $\bullet$ julho de 2019, p.45-72 
Mas o próprio Grotowski, quando ainda era vivo, já apontava para uma retomada daquilo que seria a "Arte como Apresentação" - o que fazia na sua primeira fase criativa, entre os anos 1950 e 1970 - sendo esta o outro polo da cadeia que forma as artes performativas, na qual no outro extremo estaria inserida a "Arte como Veículo", denominação esta que na verdade foi dada por outro mestre do teatro, Peter Brook (1993, p. 80).

Dessa forma, em 2007 inicia-se uma nova fase nas investigações do Workcenter com a criação, por Richards, da equipe Focused Research Team in Art as Vehicle ${ }^{4}$, que, como o nome já diz, prossegue nas questões ligadas aos estados interiores do atuante e ao "trabalho sobre si mesmo". É criada ainda a equipe do Open Program ${ }^{5}$, coordenada pelo ator e diretor italiano Mario Biagini, também diretor-associado do centro de pesquisas, e, junto com Richards, legatário legítimo da obra artística de Grotowski, cuidando dos seus escritos. Ambos os grupos desenvolvem os elementos de transição entre os dois polos que formam as artes performativas, através da criação de espetáculos e apresentações públicas, mas também com ações junto a comunidades tradicionais, imigrantes, refugiados e não-artistas, assim como com o compartilhamento de suas pedagogias pela via de cursos e palestras em diversos países.

No Workcenter, desde o começo, os cantos de tradição afro-diaspóricos eram os elementos centrais do trabalho ${ }^{6}$, e foram recolhidos, com esmero, do Vodou haitiano, do qual também alguns elementos performativos foram adaptados, tais como certos padrões de gestualidade e movimentação. Não como uma ingênua forma de imitação de um ritual, mas pura e simplesmente como pesquisa de elementos eficientes (pragmáticos, nos termos grotowskianos) que fossem úteis e adaptáveis à estrutura mental do artista cênico ocidental. Os estudos dos cantos estavam centrados em relação ao seu impacto "sobre o corpo, o coração e a cabeça dos atuantes" (Grotowski, 2012, p. 137). Estes elementos foram desenvolvidos especialmente pela colaboração com os artistas negro-mestiços haitianos Jean-Claude "Tiga" Garoute e Maud Robart, também praticantes da religião e

\footnotetext{
${ }^{4}$ Equipe Focada na Pesquisa da Arte como Veículo.

${ }^{5}$ Programa Aberto.

${ }^{6}$ No início do interesse sobre os cantos de tradição como ferramentas de trabalho sobre o performer, durante o período criativo conhecido como "Teatro das Fontes" (1976 - 1982), Grotowski empreendeu viagens à África, especialmente à Nigéria. Assim, cantos dos povos Yoruba e de outras tradições também eram parte das pesquisas nesse período, perdurando através da fase seguinte, conhecida como Drama Objetivo (1982 $-1986)$.
}

Revista da ABPN • v. 11, Ed. Especial - Caderno Temático: Cultura popular em cena: artes afro diaspóricas $\bullet$ julho de 2019, p.45-72 
fundadores do influente movimento artístico Saint-Soleil. Garoute faleceu em 2006, e a Robart, ainda viva e muito atuante na Europa, colaborou com Grotowski até os primeiros anos do Workcenter.

O desenvolvimento das pesquisas criativas, através do Open Program, chegou ao trabalho sobre os cantos negros do sul dos Estados Unidos e da música urbana ocidental, mantendo os mesmos princípios, mas a partir de uma busca que tangencia o sentido comum de teatralidade, conectada aos postulados pós-dramáticos, como ausência de personagens, textualidade fragmentada e integração de linguagens.

Os aspectos técnico-poéticos de performatividade que rigorosamente são trabalhados no Workcenter ao longo de sua história são: criação de partituras-estruturas (lógica, ações, intenções, significado e conteúdo); canto; vibração da voz; composição de movimento e ritmo; improvisação e mente desperta; improvisação dentro de uma estrutura; consciência do espaço e reação aos seus elementos constituintes; comportamento orgânico.

O período de trabalho junto ao centro de pesquisas onde Grotowski sintetizou o percurso de investigação artística de toda a sua vida enriqueceu imensamente nossa visão sobre as artes cênicas fundamentadas em poéticas afrocentradas. Este contato prático, de 2012 a 2015, de forma intensiva, com o trabalho que o Workcenter desenvolve a mais de três décadas, trouxe contribuições ao modo como concebemos a construção de uma produção teatral a partir de elementos de africanidades na cena brasileira. Insuflou novos pensamentos e procedimentos de trabalho sobre a abordagem de aspectos performativos originários de culturas tradicionais, vista a grande experiência que os continuadores de Grotowski - Richards e Biagini - registram com os cantos afro-caribenhos e afroestadunidenses. Foi a primeira ocasião, desde a criação do Open Program, que artistas negros brasileiros integraram esta equipe de pesquisa e criação ${ }^{7}$.

A colaboração junto ao Workcenter se deu a partir de uma seleção nacional ocorrida em julho de 2012, em Belo Horizonte, voltada especificamente para atores

\footnotetext{
${ }^{7}$ A necessária problematização das questões de legitimidade e apropriação cultural dentro do trabalho do Workcenter e da trajetória de Grotowski são importantíssimas, mas não há espaço para desenvolver esta ideia neste artigo, além de escapar ao seu objetivo, que se configura como a partilha de um percurso criativo em torno de uma fonte de tradição afro-diaspórica no Brasil. Venho fazendo isto em outros artigos e palestras, dentre os quais pode ser acessado o texto "Por que os cantos de tradição? E cantar, por que?: liberdade e ética no final do percurso artístico de Jerzy Grotowski”, publicado na Revista Rebento/UNESP, n. 10, p. 174-189, junho 2019: http://www.periodicos.ia.unesp.br/index.php/rebento/article/view/357
} 
brasileiros, que o Open Program buscava para integrarem a equipe e desenvolverem um novo processo criativo, o espetáculo The Hidden Sayings, baseado em cantos tradicionais afro-estadunidenses e em textos do evangelho apócrifo de Tomé.

Ao longo da participação como integrante da equipe o foco do trabalho foram os cantos de tradição do sul dos Estados Unidos, também conhecidos como Southern songs ${ }^{8}$, originários da população negra estadunidense, desenvolvidas desde a época da escravidão iniciada no século XVI neste país.

Através destes cantos são pesquisados, num primeiro plano, os seus potenciais para a criação de estados e comportamentos performativos orgânicos. Em segundo sua eficiência para a criação e organização de performances cênico-musicais. Num terceiro plano são pesquisadas as influências das Southern songs (spirituals, cantos de trabalho, cantos de prisão, hollers, shouts) sobre a música urbana ocidental (rock, soul, blues, jazz, funk). Por fim, como plano final da pesquisa, estavam os estudos sobre a palavra poética, neste caso tendo como fonte de investigação a obra de Allen Ginsberg, que expressa com grande particularidade os problemas da civilização contemporânea dos Estados Unidos. Além disso, sua obra tem grande ligação com a música afro-estadunidense, tendo muitos dos seus poemas interpretados, alguns em sua própria voz, com grupos de jazz, blues e rock. É emblemática esta frase atribuída a ele: "Se a América, tem uma alma é por causa do soul"'.

Para estes poemas foram criadas e desenvolvidas, pelos performers mais antigos da equipe, composições musicais originais, dentro dos gêneros acima citados. Da combinação entre os cantos tradicionais, os gêneros musicais urbanos e a poesia de Ginsberg resultaram os seguintes espetáculos: Electric Party Songs, Electric Party, I Am America, Not History Bones - A Poetry Concert e o já mencionado The Hidden Sayings, que utiliza Southern songs e textos sacros. Atuamos em todos estes espetáculos, com performances na Itália, Romênia, França, Canadá e Brasil.

A Plataforma Garimpar... nasceu também do interesse direto em prosseguir o desenvolvimento das pesquisas pessoais que se abriram durante o trabalho junto ao Workcenter. Essa continuidade pretendeu desdobrar as investigações lá desenvolvidas sobre as relações entre a performatividade contemporânea e os cantos de tradição afro-

\footnotetext{
${ }^{8}$ Canções sulistas.

${ }^{9}$ Do original: "If America has a soul is because the soul."
} afro diaspóricas $\bullet$ julho de 2019, p.45-72 
diaspóricos através de elementos essenciais da cultura brasileira: a sonoro-musicalidade e a palavra poética de origem Bantu, que estão nas raízes da língua e da música popular nacionais.

Com o que foi estudado e descoberto através dos elementos técnicos abordados, bem como com novas compreensões da relação entre corpo e presença cênica alcançadas no trabalho com os cantos negros do sul dos EUA e suas potencialidades como geradores de organicidade em situações performativas, é que foi desenvolvida a pesquisa sobre os vissungos, objeto central dentre todos os projetos da plataforma ao longo de cinco anos.

\section{VISSUNGOS: HISTORICIDADES, MITOPOÉTICAS E FUNDAMENTAÇÃO POÉTICA DA PESQUISA CRIATIVA}

Os vissungos ${ }^{10}$ são cantos de tradição afro-brasileiros, nascidos entre os escravizados de origem Congo, Matamba, Ndongo e Benguela, que habitavam no interior de Minas Gerais, na região de extração de minérios preciosos, que entre outras inclui Diamantina, Serro e outras cidades circunvizinhas.

São veículos de preservação das línguas oriundas da África, de tronco Bantu (kimbundu, kicongo e umbundu), de fundamental importância para a construção da língua portuguesa do Brasil, ao conjugar também línguas africanas, o português rural e elementos linguísticos e sonoros ameríndios. São centrais para o entendimento do percurso de formação das musicalidades afro-brasileiras e da música popular em geral.

Não são cantos de trabalho, como uma primeira escuta etnomusicológica generalista poderia supor, mas

Os vissungos são cantos de força. Foram originalmente cantados durante o trabalho de mineração nos rios de Minas Gerais no início do século dezoito. (...) Contudo, se tivermos em mente que as pessoas que os cantavam estavam no exercício de suas atividades sob severa coerção física, ao chamá-los de "cantos de trabalho" dificilmente estaríamos refletindo o ponto de vista do sujeito que cantava. (Carvalho, 2009, p. 21)

${ }^{10}$ Do umbundu ovisungu,pl. de ochisungu, significando canto, cantiga, cântico. (LOPES, Nei. 2102, p. 255). 
Daí que não é errôneo afirmar que também são cantos de escravidão, que expressavam as mais diversas situações da vida cotidiana do africano desterrado e seus descendentes, que foram trabalhar nas minas e lavras de ouro e diamante, escravizados pela Real Extração, o serviço de mineração oficial da Coroa Portuguesa. Posteriormente, com o fim do Brasil Colônia, continuaram nos cantares de garimpeiros e faiscadores, que perseguiam o sonho de melhores condições de vida na busca dos mesmos minérios preciosos. Por fim, estes cantares bantus se preservaram em diferentes ritos cotidianos e comunitários, como os enterros. ${ }^{11}$

Estes cantos da região congo-angolesa no Brasil ocorreram no Alto Jequitinhonha, norte de Minas Gerais, região margeada pela Serra do Espinhaço, a partir da chegada dos primeiros escravizados da Costa da Mina - conhecedores desde África das tecnologias metalúrgicas e de mineração ${ }^{12}$ - em fins do século XVII, sendo ainda oralmente transmitidos até meados do século XX.

É justamente o processo de rareamento da transmissão destes cantos, dado especialmente pelo desaparecimento dos contextos originais onde eles se sustentavam o garimpo e o transporte de mortos aos cemitérios pelas estradas - que os colocou em franco processo de extinção como um dado fulcral do processo de transição dos elementos diretos de africanidade para a construção de uma afro-brasilidade dentro de um conceito amplo de arte afro-brasileira. Compreendemos aqui o cantar como performance com tecnologia orgânica e produto intencional de pensamento estético, e não banalmente como expressão de uma emotividade subjetiva do afro-brasileiro, como tenderiam a resumir olhares datados e escutas folclorizantes das produções culturais de matriz africana.

Enquanto manifestações legítimas em um contexto cultural específico é que podemos considerar os vissungos como uma tradição em extinção, ao menos de um ponto de vista estritamente etnográfico. Pois não há mais garimpo - a loteria federal tomou seu lugar. Não se caminham mais quilômetros carregando um caixão para se fazer um enterro - o carro da funerária faz este serviço. E, também, porque hoje não existem mais tantos legítimos vissungueiros, que os conheçam em seus fundamentos, como a sua ritualística,

\footnotetext{
${ }^{11}$ As específicas práticas funerárias indicam relações diretas dos vissungos - inclusive etimologicamente - com os tsungos, cantos fúnebres da etnia centro-africana Côkwe.

12 “(...) De acordo com os estudos demográficos mais recentes, não parece restar dúvidas de que os africanos vindos da Costa da Mina representavam algo em torno da metade dos escravos presentes nas Minas Gerais nas décadas iniciais da exploração, o que torna provável que seus conhecimentos sobre a mineração tenham colaborado para o bom andamento das atividades" (Gonçalves, 2004, p. 9 - 10).
} 
as formas de execução, ou, como dizem os mais velhos, "enrolando a língua", quer dizer, falando com o conhecimento do significado das palavras com origem nas idiomáticas Bantus. Ivo Silvério da Rocha, de Milho Verde, distrito de Serro, é considerado o último mestre vissungueiro vivo, e sua biografia e importância no panteão da cultura afrodiaspórica no Brasil levou a Plataforma Garimpar... a dedicar a sua segunda fase criativa a ele, como veremos mais adiante.

Auguste de Saint-Hilaire, naturalista francês, que realizou expedições ao Brasil na segunda metade do século XIX, é quem narra pela primeira vez, em suas cartas de viagem, a existência destes cantos, no entanto, sem ainda dar a eles a denominação específica como hoje são conhecidos. Entre algumas passagens de seus inúmeros relatos de viagem, encontram-se fragmentos como este: “(...) Reunidos em grande número esses infelizes se divertem em seus trabalhos; cantam em coro canções de suas terras (...)" (Saint-Hilaire, 1941, p. 10). Ingenuidades do branco francês à parte, sigamos adiante.

O filólogo mineiro Aires da Mata Machado Filho encontrou os vissungos em 1928, no distrito diamantino de São João da Chapada, e foi quem pela primeira vez os referenciou utilizando essa nomeação local. Registrou em partituras, entre as décadas de 1920 e 1930, 65 vissungos, publicando, em 1943 o livro "O negro e o garimpo em Minas Gerais", um estudo etnográfico que além dos cantos registrava o ambiente sociocultural ao redor das práticas do garimpo, a mineração dita clandestina, desdobramento natural das grandes explorações da Real Extração no período escravocrata, ocorridas entre os séculos XVII e XIX.

No entanto, sua pesquisa foi descontinuada, em âmbitos acadêmicos, desde a publicação do livro, havendo um lapso de mais de 60 anos, até 2001, quando o interesse por esta tradição foi retomado oficialmente, especialmente por pesquisadores da Faculdade de Letras da Universidade Federal de Minas Gerais (FALE-UFMG), destacando-se Lucia Valéria do Nascimento, renovando as pesquisas de campo. Em contraposição, sabe-se que Spírito Santo, pesquisador e músico fundador do ilustre e quase desconhecido "Grupo Vissungos" no Rio de Janeiro da década de 1970 (e ainda ativo!) mantém uma pesquisa pessoal não-acadêmica desde 1975, que ainda carece de apoio para publicação de seus resultados.

Nessa retomada do interesse sobre os vissungos no presente século pela universidade, as pesquisas atuais encontraram, na memória dos últimos cantadores ainda 
vivos reminiscências de apenas 14 cantos dos 65 registrados por Aires da Mata. O que significava um evidente processo desaparecimento de uma importante afro-matriz da cultura popular brasileira, ainda mais se considerarmos que esses cantadores já possuíam idade avançada.

O fim dos contextos socioculturais que sustentavam a prática dos vissungos romperam seus processos de transmissão transgeracional. Daí depreendemos que esta impossibilidade de transmissão se deu - e ainda se dá - tanto pela falta de interesse por parte dos potenciais herdeiros (familiares e outros membros legítimos da comunidade), como também pelo imenso cuidado que os mestres possuem em relação ao ensino destes cantos, que guardaram com a consciência de que são cantos rituais ancestrais, que representam o que ainda resta de herança imaterial legítima dos primeiros africanos em seus meios. Desta forma não havendo a transmissão para pessoas de fora das suas comunidades.

Nesse ponto estão as principais problemáticas sobre a preservação/manutenção desta tradição, que tensionam os debates sobre transmissão, preservação, transcriação e apropriação cultural, uma vez que a manutenção dos cantos, do final do século XX a este início de século XXI, vem se dando pela ação de pesquisadores das ciências humanas e etnomusicólogos, além de artistas que, como nós, veem e ouvem nos vissungos uma profunda fonte de poética e estética afro-brasileira de amplo efeito sobre os sentidos do espectador-ouvinte.

Os vissungos eram cantados normalmente à capella, sem acompanhamento instrumental. Mas Machado Filho e gravações feitas em 1944 por Luis Heitor Correa de Azevedo (com suporte técnico e financeiro da Biblioteca do Congresso dos EUA) registram a presença de uma percussão improvisada a partir de ferramentas de trabalho do garimpo (enxadas, bateias).

Os aspectos rítmicos, melódicos e harmônicos ainda são pouco compreendidos, ainda que possam ser observados a partir de suas transmigrações nas congadas, moçambiques e catopês, além de outras manifestações das culturas bantu-brasileiras. Esta carência levou a muitos arranjos e releituras, tendo por base, principalmente, o repertório gravado no álbum antológico "O Canto dos Escravos", que baseado fundamentalmente nos aspectos melódicos e recriações rítmicas, não atingiu a complexidade polifônica e vibratória dos cantos em seus contextos próprios. 
Gravado em 1982, pelo selo da Gravadora Eldorado, este disco foi baseado em 14 vissungos do repertório coletado por Machado Filho, sendo interpretados magistralmente por Clementina de Jesus, Geraldo Filme e Tia Doca. Porém, pela lógica fonográfica comercial, não foi fiel às características originais dos vissungos porque “(...) a base rítmica escolhida não repetiu o padrão rítmico original, mas usou um tipo de ritmos binários generalizados da umbanda [e/ou Candomblé Angola], tais como o barravento (...)" (Carvalho, 2015, p. 26, grifo nosso). Padrões que não correspondem à rítmica real dos vissungos, mais próxima do candombe, como Carvalho aponta, mas também das congadas, como observamos ao longo das nossas investigações e criações artísticas.

\section{GARIMPAGEM - PESQUISA CRIATIVA DOS VISSUNGOS}

A primeira parte da primeira fase do trabalho aconteceu em viagem de pesquisa de campo, entre janeiro e fevereiro de 2016, para o estado de Minas Gerais, em São João da Chapada e Quartel do Indaiá, respectivamente distrito e quilombo no município de Diamantina, e em Milho Verde, distrito do município de Serro. Nesses locais podem, ainda hoje, serem encontrados os últimos herdeiros que guardam os vissungos em suas características originais, recebidos pela transmissão direta dos velhos mestres vissungueiros ou, tão somente, pela escuta atenta dos cantos, quando crianças, nas lidas do garimpo ou nos ritos de transporte dos mortos nas estradas, de seus pequenos lugarejos até os cemitérios oficiais das localidades maiores.

A intenção nesta pesquisa de campo era a coleta dos cantos em suas purezas expressivas, no que concernia aos aspectos melódicos, rítmicos e harmônicos, tanto na voz quanto nos acompanhamentos instrumentais. Foi a partir do contato direto com os portadores dos vissungos em sua expressividade original que, juntamente com o auxílio de gravações fonográficas e materiais audiovisuais, pudemos nos aproximar e desenvolver os primeiros elementos de performatividade referentes ao caráter das vocalidades tradicionais dos cantadores de vissungos.

As pesquisas partiram da busca de contato com estes mesmos cantadores, durante o período de um mês, através de registro audiovisual. Intencionávamos, após estes contatos, construirmos uma base sólida de referências sonoro-vocais e imagéticas para o 
posterior momento - na volta para São Paulo e para a rotina de criação artística - de prosseguir no projeto de transcriação ${ }^{13}$ dos demais cantos registrados em partitura por Machado Filho e nas antigas e precárias gravações fonográficas que tivemos acesso. Com a experiência de campo pudemos ter uma orientação mais precisa para esta tarefa transcriativa, através da apreensão de alguns dos elementos estruturais e interpretativos dos cantares vissungueiros.

Os cantos foram transcriados a partir desta pesquisa in loco e da utilização do material coletado por Machado Filho, principal registro escrito existente sobre esses antigos cantos, que traz um razoável repertório partiturizado no acima mencionado " $\mathrm{O}$ negro e o garimpo em Minas Gerais".

(...) Reunimos e anotamos o documentário relativo ao dialeto crioulo, inclusive sessenta e cinco cantigas, com a letra, tradução e música. Como se vê, só a salvação dos "vissungos" tem indisfarçável alcance etnográfico. Até aos compositores e musicólogos há de interessar a nossa contribuição. (Machado Filho, 1985, p. 15)

Também foram utilizadas três gravações realizadas em 1944 pelo pesquisador acima mencionado L. H. C. de Azevedo, que encontramos no disco Music of Ceará and Minas Gerais. Estas gravações são parte de um projeto maior financiado nos anos de 1940 pela Biblioteca do Congresso (The Library of Congress), dos Estados Unidos, sob coordenação de John Lomax, nome fundamental na pesquisa etnomusicológica. Este projeto visava uma ampla coleta e catalogação das expressões afro-americanas nas três regiões do continente. Alguns outros fonogramas deste histórico material acerca dos vissungos também foram cedidos gentilmente pela artista e pesquisadora Andreia Adour

\footnotetext{
${ }^{13} \mathrm{O}$ conceito de transcriação, adotado dentro deste processo de pesquisa e criação, nos foi apresentado pela linguista e poetisa Sônia Queiróz (FALE - UFMG). Ele advém de nomenclatura criada por Haroldo de Campos (1929 - 2003), poeta e tradutor brasileiro, que em relação ao processo de tradução de autores estrangeiros defendia que o tradutor deveria manter um diálogo criativo com o espírito da obra original, buscando imagens equivalentes em sua língua natal para aquelas apresentadas em outros idiomas, não se atendo somente às acomodações gramaticais e semânticas do processo de tradução tradicional. Assim, o processo transcriativo equivale a uma reescrita paralela da obra original, em estrita conexão com as intenções do autor, mas sem que o tradutor abra mão dos seus afetos subjetivos. No caso dos vissungos, ao se tratarem de cantos também transcriados ao longo da tradição oral - uma vez que muitas das palavras não existem em nenhum dos vocabulários das línguas Bantus, sendo recriações afetadas pelo português rural e pelas idiomáticas ameríndias advindas do contato dos africanos com os povos nativos do Norte de Minas Gerais - uma postura transcriativa neste processo artístico revelou-se extremamente natural.
} 
(UFRJ) no decorrer da pesquisa. Adour adquiriu uma série destas gravações, calculadas em mais de 100 registros, junto à Library of Congress, mediante compra dos arquivos.

Completando as fontes que alimentaram o processo criativo, utilizamos ainda registros bibliográficos, fonográficos e audiovisuais doados pelas pesquisadoras e docentes da UFMG Sônia Queiróz e Glaura Lucas, assim como por Lúcia Valéria do Nascimento, a partir de seus acervos pessoais. Entre estes materiais destacam-se:

- Vissungos: cantos afrodescendentes em Minas Gerais (revista) e A África no

Serro Frio - Vissungos: uma prática social em extinção (dissertação);

- Vissungos do Rosário e Congado Mineiro (CDs),

- Terra deu, terra come (filme) e Baú (vídeo).

O apoio teórico do trabalho foi dado pela leitura das atuais pesquisas etnográficas, antropológicas e etnomusicológicas, realizadas sobre os vissungos, mas também sobre os elementos cosmoperceptivos das tradições Bantu, para os quais contribuíram para o conhecimento estudos junto ao historiador e etnomusicólogo Rafael Galante e a leitura de publicações como as de Kazadi wa Mukuna (Contribuição Bantu na Música Popular Brasileira) e Nei Lopes (Novo Dicionário Banto do Brasil).

\section{LAPIDAÇÃO - PESQUISA CRIATIVA E TRANSCRIAÇÃO SONORO- MUSICAL}

Após o primeiro entendimento dos vissungos em seus aspectos sociais e históricos seguimos avançando para uma compreensão dos fundamentos sonoro-musicais dos cantos e uma transcriação o mais próxima possível das suas características originais. Esta parte do trabalho, desde o seu início, tem ocorrido em São Paulo (Capital e ABC Paulista), trabalhando individualmente e com atrizes e atores locais.

Esta transcriação não significou - e continua não significando - a realização de um pretenso resgate de uma tradição no sentido de apenas salvá-la do esquecimento ou do desaparecimento, formando novamente seu corpus original. Significa que esta pesquisa criativa busca ser uma ação de presentificação e atualização da potência orgânica de uma forma artística da tradição, sem ser museológica. É regida por princípios técnicopoéticos adequados ao nosso tempo artístico, sendo que a práxis está baseada em fundamentos da artesania das artes cênicas, filiadas à corrente que Grotowski nomeou 
como técnica ou linha orgânica ${ }^{14}$. O que buscamos fazer foi, simultaneamente, uma criação original dentro de uma forma tradicional, a partir do nosso encontro com ela, que também foi confronto, ajustamento, conversa e acordo.

Assim, a transcriação dos cantos foi suleada pelas seguintes marcas:

1. Melodia: trabalho sobre o domínio preciso das linhas dos cantos, em suas características tonais e escalares;

2. Pronúncia: estudos sobre as línguas Bantus e a reinterpretação fonética específica destas na região geográfica onde os vissungos se desenvolveram;

3. Prosódia: prática sobre as vocalidades específicas de cada canto, a maneira da palavra ser expressa, a partir dos registros feitos na pesquisa de campo e na escuta de gravações registradas por outros pesquisadores;

4. Rítmica: estudos sobre os ritmos originais dos cantos, suas origens e suas específicas variações;

5. Polifonia vocal: investigação das formas comunitárias de realização dos cantos, a relação entre as diferentes vozes nas diferentes formas de vissungos,

6. Acompanhamento instrumental: pesquisa sobre os instrumentos de acompanhamento dos cantos, em seu contexto original e nas possibilidades de atualização.

Trabalhando orientado por estes parâmetros de busca destes elementos pretendemos nos ater com fidelidade máxima aos princípios originais da musicalidade destes cantos, suas vocalidades matriciais. No atrito com elementos performáticos atuais, oriundos da experiência obtida durante a atuação no Workcenter of Jerzy Grotowski and Thomas Richards, exploramos a capacidade de diálogo vivo e reverente da cena contemporânea com fundamentos performativos de uma tradição em vias de um iminente processo de extinção nas suas comunidades originárias. Processo tal que, ainda que não possa ser impedido de acontecer em seus contextos natais, ao menos pode ser refreado ou mesmo impedido em contextos urbanos, uma vez percebida a potência de atualização de memória e devir ancestral desses antigos cantos, a partir do seu amplo poder de

\footnotetext{
${ }^{14}$ Se refere ao processo de articulação do comportamento psicofísico coerente do organismo humano em performance. Esta articulação deve se dar, paradoxalmente, dentro de uma estrutura artificial, ou seja, a montagem cênica, no nível corpóreo-vocal do atuante ou das formalidades do evento performativo. Seu oposto seria a técnica ou linha artificial, presente nas formas performativas codificadas, manifestas de inúmeras maneiras nos diferentes contextos culturais, por exemplo, as danças de Orixás. (GROTOWSKI, 1982, p. 2)
} 
reverberação como legítima arte afro-brasileira, através de novas práticas integrativas entre cena e música.

\section{POLIMENTO - PROCESSO DE CRIAÇÃO DOS ESPETÁCULOS DA TRILOGIA VISSUNGUEIRA}

Foram criados três espetáculos a partir do repertório de vissungos que ao longo desses cinco anos de pesquisa criativa estão sendo trabalhados. Em 2016, Episódio I: Uenda-congembo (morrer); em 2018, Episódio II: Mileke entre Pedras e Piercings, e em 2019, Episódio III: Banzo e os Filhos dos Antigos.

Distribuídos nestes espetáculos estão presentes: 38 dos 65 cantos registrados por Machado Filho, 3 retirados das gravações de Azevedo, 2 do repertório pessoal de Seu Ivo, 1 do repertório pessoal de Seu Pedro de Alexina, 1 do repertório tradicional de canções de Angola e 1 do Congo, e outros dois transcriados por jovens atores, Jean Rocha e Jéssica Pina, que participaram do projeto na sua segunda fase.

Todos estes cantos foram inseridos em específicas sequências cênico-musicais, desenvolvidas conforme as relações observadas entre os conteúdos dramatúrgicos totais (de cada espetáculo e de cada cena em particular) e as diferentes naturezas de cada canto (conforme suas utilidades dentro das ritualidades ou dos afazeres da vida cotidiana), mas também conforme a poética apresentada em seus versos e suas reverberações imagéticas no corpo dos atuantes-cantantes.

Os vissungos, conforme relata o mestre Antônio Crispim Veríssimo, um dos últimos mantenedores dessa tradição, falecido em 2008, são divididos nas seguintes formas:

- Cantos de morte e caminho: para o acompanhamento de velórios e funerais

- Cantos de pedir ajuda: quando é necessário descansar do transporte do féretro

- Cantos de insulto: para provocar os inimigos do falecido e convocá-los para o enterro

- Cantos de chegada na igreja e no cemitério: para a unção e o enterro

- Cantos de multa: para as relações de troca no trabalho do garimpo

Por outro lado, Machado Filho, em seu livro, apresenta uma divisão destes cantos em outras categorias, que mesmo que ainda não seja suficiente para dar conta de agrupar 
o sentido de todos os cantos registrados, funciona como um norteador inicial para entender a relação funcional entre canto e ação intencional, ou seja, para o que aquele canto era empregado. Qual o seu uso funcional no contexto do garimpo, das tarefas diárias e das relações subjetivas com os fenômenos naturais e a ciclicidade do tempo.

Foi a partir dessas duas propostas organizacionais, a indicada por Seu Crispim e a sugerida por Machado Filho, que estruturamos a presença dos cantos nos espetáculos, quase como que uma dramaturgia independente dentro da grande dramaturgia que dá o sentido específico de cada obra teatral criada.

Buscamos desenvolver dramaturgias que revelassem os diferentes usos dos cantos, mas não para ilustrações destes, e sim com a construção de situações de equivalência, onde esses usos/funções tradicionais pudessem ser compreendidos pelo público de forma simbólica, e não puramente documental, como curiosidade passadista ou folclore pitoresco.

Evitamos cenas baseadas em tentativas de mímesis de situações ordinárias ou de reconstruções de caracteres típicos do contexto original dos vissungos, justamente para nos afastar de qualquer atmosfera de folclorismo ou arquivismo que o trabalho com esse material pudesse trazer. Trabalhamos fundamentalmente sobre as evocações que cada canto trazia, dentro da categoria a que pertencia (de caminho, de morte, de amanhecer, de multa, etc.) e com seu poder de disparar precisas atitudes de memória e imaginação nos performers. Este é um ponto do trabalho diretamente conectado com as proposições contemporâneas de criação cênica orientadas pela dramaturgia atoral, onde a práxis desenvolvida durante nosso período de atuação no Open Program se fez - e ainda se faz - bastante presente, mas adaptada às necessidades específicas e realidades próprias das criações da Plataforma Garimpar.... Mas, além disso, considerando o aspecto nãomimético acima citado, podemos dizer que o trabalho sempre esteve em consonância com este mesmo princípio presente na arte tradicional africana:

(...) As formas de representação africana não levam em conta a imitação do real, mas a significação do sobrenatural através do material. Não há compromisso em reprodutibilidade dos caracteres humanos, e, sim, de forças da natureza, que carregam um arquétipo do humano, com características físicas próximas do realmaterial. Desse modo, o que se expressa [...] é justamente a comunicação e ligação do material, terreno, com o sagrado. Arte africana é uma das formas de conexão de toda uma cosmovisão particular. Expressar-se artisticamente para se conectar com o sagrado. Não há falhas na construção dessas materialidades, 
porque aqui não há um modelo específico a ser alcançado. A criação precede uma autorização sagrada para a execução, bem como o manejo de matéria prima específica (Ferreira, 2019, p. 89-90).

No processo criativo de cada um dos três espetáculos havia sempre o atrito positivo entre as temáticas de cada obra - construção de identidade negra, tradição e contemporaneidade, banzo e o mito da democracia racial, respectivamente - e nisso a potência de cada canto surgia e preenchia a ação com uma densidade subjetiva a mais para a/o atuante-cantante, pois cremos que cada vissungo traz cargas histórico-sociais e poéticas imensas, que estão presentes nas qualidades vibratórias que possuem e revelamse em suas palavras, rítmicas e melodias. Qualidades vibratórias que contém as memórias daqueles que cantaram estes cantos, desde os primórdios do cantar nas paisagens centroafricanas, até as vivências diaspóricas nas lavras mineiras. São "cantos de experiência" (Jay, 2009, p. 15), muito mais além que somente cantos de escravidão ou trabalho.

Um tema poético arquetípico orbitou sempre todas as produções: a morte. Talvez porque estes cantos tenham feito parte também das tecnologias para a "boa morte" dentro das tradições Bantu no Brasil. Dialeticamente os vissungos cantam a sua própria morte enquanto uma manifestação cultural da memória viva afro-brasileira. Melancolicamente cantam o fim de uma existência praticamente ignorada por tantas gerações de brasileiros até hoje.

\section{PRIMEIRA TALHAGEM - EPISÓDIO I: UENDA-CONGEMBO (MORRER)}

Através dos cantos, suas historicidades e mitopoéticas, e das reminiscências e associações que despertaram, o processo criativo deste espetáculo desenvolveu reflexões sobre temas complexos como a morte, ancestralidade, identidade racial, pertencimento, o fim de uma tradição e suas possibilidades de permanência e ressignificação.

Esta obra cênica propôs-se também a ser um primeiro estudo de alternativas poéticas e estéticas ao teatro musical brasileiro contemporâneo, a partir de pressupostos visuais, sonoros e de atuação distintos do que se tem praticado massivamente nesta forma teatral atualmente, pautados em carimbos de referência "broadwayana". A busca foi - e ainda é - por uma cena baseada em epistemologias do pensamento africano, fundamentalmente das cosmopercepções Bantus, que envolvem maneiras distintas de 
relação com o som-música, a palavra e o espaço-tempo. Estes aspectos relacionais, juntamente com o que temos nomeado como poética da ancestralidade, são matérias principais dos estudos que atualmente desenvolvemos na tese de doutoramento "Transcriações de tradições: presença e movência de elementos de africanidades em cenas contemporâneas", em curso na Universidade de São Paulo.

Em termos dramatúrgicos a obra tratou das tensões étnicas e de busca de identidade cultural vividas na contemporaneidade, partindo do diálogo criativo com os vissungos. Tendo como pano de fundo o ambiente da mineração do diamante e as procissões dos enterros, e em meio ao jogo entre memórias pessoais, dados históricos e metáforas poéticas, foi traçado um caminho de reconstrução da relação perdida e desconhecida entre ancestralidade e atualidade, no corpo e na vida interior do ator, que sozinho em cena, mas acompanhado por "vozes falando em sua voz", trafega por diferentes figuras presentes no universo dos antigos cantos e em seu mundo íntimo, criando uma auto-etnoficção.

Esta auto-etnoficção está em constante diálogo crítico com os textos e as figuras de Machado Filho e Auguste de Saint-Hilaire. Além disso, dialoga com fragmentos de poemas do moçambicano José Craveirinha, que ajudam a construir a ideia de resistência cultural presente na peça, com textos que remetem às lutas anti-coloniais em seu país.

Por fim, textos próprios entremeiam e ligam toda a dramaturgia, trazendo memórias de infância e experiências familiares, diluídas em um jogo constante de planos narrativos, entre situação presente (alguém que se prepara para a morte), reminiscências oníricas (relatos de um sonho), visagens (a visita de um ancestral) e o relato ficcionalizado da experiência pessoal em si (a materialização da subjetividade).

A ação se desenrola num corredor entre duas arquibancadas colocadas frontalmente, que, com os recortes precisos da iluminação e as intenções da atuação, remete a uma pequena casa de pau à pique onde se desenrola a ação presente, mas que no fluxo de memórias e imaginações se torna uma estrada no interior de Minas Gerais, um quarto de hotel, uma maternidade, uma igreja ou um cemitério.

O trabalho sonoro-musical é focado no cantar dos vissungos e no uso de objetos ligados ao contexto da mineração (como acima mencionado, o único acompanhamento instrumental existente nas origens desses cantos no Brasil), tais como bateia e enxada. Também são explorados instrumentos percussivos originários das culturas Bantus 
(berimbau e mbira), como forma de se construir uma coerência timbrística na dramaturgia musical em termos etnomusicológicos. Além disso, são exploradas sonoridades advindas dos objetos e materiais utilizados na obra, como forma de criação de uma totalidade orgânica do espetáculo - que não se utiliza em nenhum momento de música mecânica tais como água e palha.

Esta criação contou com a importante colaboração artística de Pedro Pires, diretor da Cia. do Feijão, de São Paulo, que através de um projeto de orientações artísticas realizado pelo grupo, acolheu a minha proposta, e, a partir de um olhar distanciado, porém sensível, como pessoa branca, trouxe provocações essenciais para o resultado final alcançado.

\section{Figura 1: Cena de Episódio I - Uenda-congembo (morrer)}

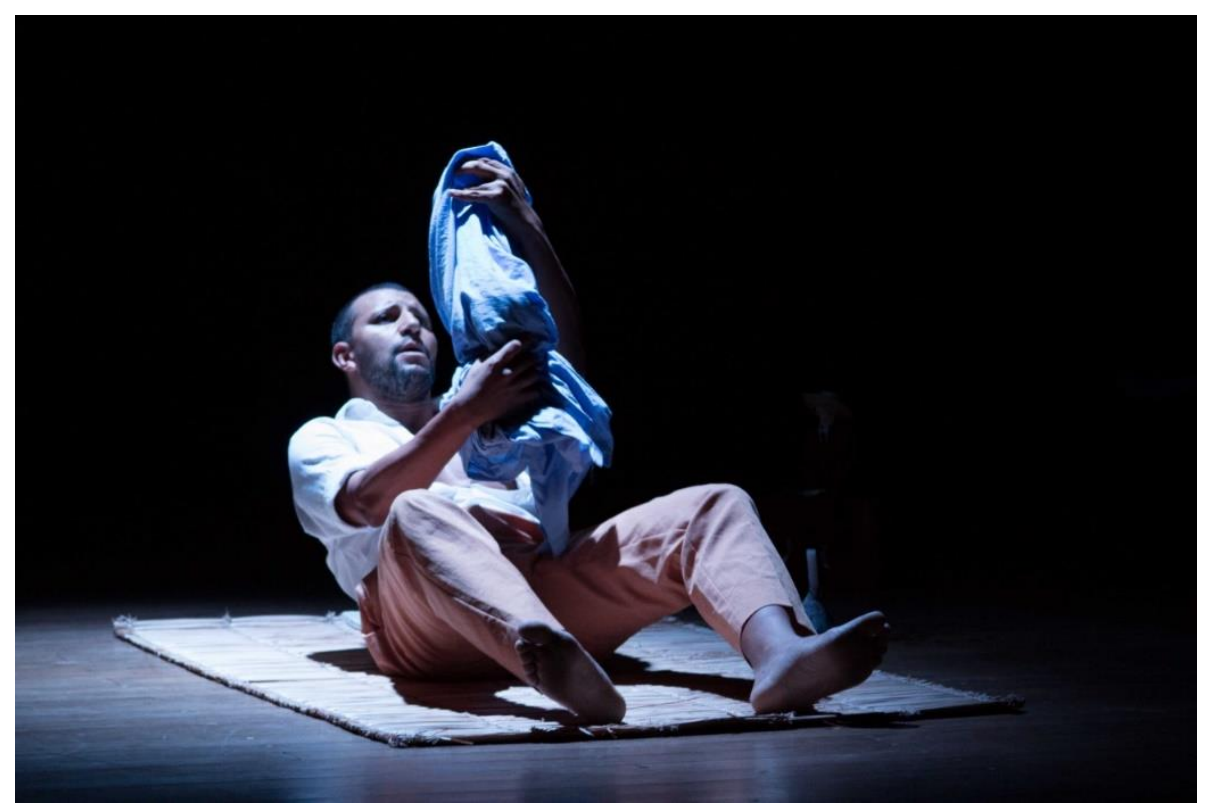

Fonte: Funarte SP - Abril/2018 - Foto: Suellen Leal

\section{SEGUNDA TALHAGEM - EPISÓDIO II: MILEKE ENTRE PEDRAS E PIERCINGS}

A segunda obra da "Trilogia Vissungueira" aprofundou os estudos do repertório conhecido de vissungos (por partitura e gravações), suas variações em outros contextos e suas transcriações em novas experiências linguísticas e sonoras. Nesta nova montagem 
nos ativemos à direção, dramaturgismo, concepção sonoro-musical e operação de luz e som.

A pesquisa criativa se desenvolveu em torno das memórias de Ivo Silvério da Rocha - o último mestre vissungueiro - no período em que, vindo da pequena vila de Milho Verde, viveu na cidade de São Bernardo do Campo, região do ABC Paulista, no estado de São Paulo, entre 1972 e 1979. Neste período trabalhou em metalúrgicas e tecelagens, além de experienciar a vida social e cultural da região e seu entorno - também a Capital - como jogador de futebol amador e frequentador de bailes. Viveu o ambiente da ditadura militar, testemunhando as greves metalúrgicas e a repressão no estado de exceção.

Como na sua terra natal, manteve o hábito das grandes caminhadas, conhecendo muito bem a região do Grande $\mathrm{ABC}$ a pé. Tudo isto sendo o portador anônimo deste elemento de africanidade da mais alta importância para a formação do povo brasileiro.

Sua mestria também está em ser capitão de Catopê, um dos grupos que compõem a guarda de Nossa Senhora do Rosário, e que faz parte do ciclo das Congadas.

Estas memórias de lugares e experiências urbanas e rurais foram registradas no livro autobiográfico "Memórias de um Catopê", publicado em 2015. Com base neste livro estas memórias foram revisitadas por jovens atores de São Bernardo do Campo, estudantes do CLAC (Centro Livre de Artes Cênicas), escola livre de formação artística onde lecionamos entre 2012 e 2017, último ano de seu funcionamento. Estes artistas iniciantes (Adriellen Neves, Débora Vaz, Jean Rocha, Jéssica Pina e Serafim Mariano) exploraram as possibilidades artísticas dos vissungos a partir do encontro provocativo com esta tradição quase perdida.

No encontro entre os cantos seculares e seus corpos cantantes de jovens da era tecnológica, emergiram diálogos entre as experiências de um mestre da cultura popular afro-matricial e as experiências de seus "irmãos mais novos” (mileke, em língua kicongo), que em meio aos ritmos e impactos da vida urbana de uma cidade industrial como São Bernardo do Campo, buscaram encontrar o sentido e o valor desses velhos diamantes invisíveis, mas audíveis e capazes de calar fundo, com suas vibrações, na totalidade psicofísica humana, gerando experiências subjetivas concretas.

O encontro desses jovens atores periféricos com a tradição dos vissungos gerou novas transcriações dos cantos, e, através do atrito com certos pressupostos da cena 
contemporânea (linearidade fragmentada, liminaridade arte/vida, linguagens híbridas) colocou em contato a realidade da vida urbana atual com uma das fontes mais importantes da herança africana no Brasil, investigando as origens de sua afrodescendência e as relações possíveis de serem estabelecidas com uma cultura antiga através dos seus próprios referenciais criativos e técnicos como indivíduos pertencentes às primeiras gerações do século XXI.

Os jovens das regiões de Minas Gerais onde os vissungos aconteciam pouco mantiveram em movimento a tradição destes cantos, logicamente afetados por fatores socioculturais que não temos espaço para refletir aqui, mas que envolvem também as tensões dinâmicas entre as transmissões orais e o impacto do mundo digital-virtual na contemporaneidade. Restando apenas este mestre da tradição vissungueira, que por sorte caminhou na mesma região em que tanto nós quanto estes jovens atuantes vivemos, não hesitamos em ir ao encontro deste tesouro vivo que estava desde sempre tão paradoxalmente ao nosso alcance.

Nestes cantos de vida e morte os jovens do ABC puderam refletir sobre suas próprias perdas e sobre todas as perdas da existência humana. Procuraram pelos sinais dos espíritos ancestrais, que poderiam estar caminhando pelas mesmas ruas que o velho vissungueiro passou, e que agora, com seus tênis e bikes, eles mesmos passavam em seus dias comuns, entre suas casas, seus trabalhos, suas escolas, seus "rolês".

Muitas imagens compuseram a paisagem desta jornada e garimpagem pessoal na busca por "Seu Ivo", um mantenedor e reinventor da África no Brasil, que conheceu esta cidade antes mesmo que estes jovens nascessem. O garimpo de diamantes, onde o mestre vissungueiro conheceu o sentido da palavra trabalho. O futebol nos campos de várzea da periferia do $\mathrm{ABC}$, onde jogou, em muitos times, em muitas posições, com diversos números de camisa. Os salões de baile que frequentava para satisfazer seu gosto pela dança. As longas estradas de suas andanças a pé sobre o asfalto urbano. A presença invisível dos Catopês, seus movimentos, seus sons, suas vestes, que o mestre trazia dentro de si, desde a pequena vila de Milho Verde, onde cumpria sua devoção à Nossa Senhora do Rosário, santa-rainha dos homens pretos.

Os vissungos do repertório oficial da pesquisa e outros que criaram a partir do diálogo com as estruturas formais e subjetividades despertas pelos cantos foram os orientadores dos jovens artistas - em sua maioria negros - na construção de suas próprias 
presenças no século XXI. Afinal estes cantos também guardam instruções de liberdade. Poderiam encontrar estes diamantes no rio morto, o Tamanduateí que atravessa o ABC? Nas fábricas abandonadas? Nos últimos campos de várzea que ainda resistem às especulações imobiliárias do "progresso"?

$\mathrm{Na}$ jornada desse segundo espetáculo buscamos estas respostas e encontramos questionamentos sobre nossas próprias vidas numa grande cidade moderna em atrito com os valores de uma intuída ancestralidade. E ao cantar os velhos vissungos e explorar as memórias paulistas do derradeiro mestre desta arte, fomos questionados pela tradição que nós mesmos imaginamos. Qual o sentido de falar do passado nos tempos de hoje? Qual a mais profunda herança que a África nos deixou? Onde está a África em nós, de fato?

\section{Figura 2: Cena de Episódio II - Mileke entre Pedras e Piercings}

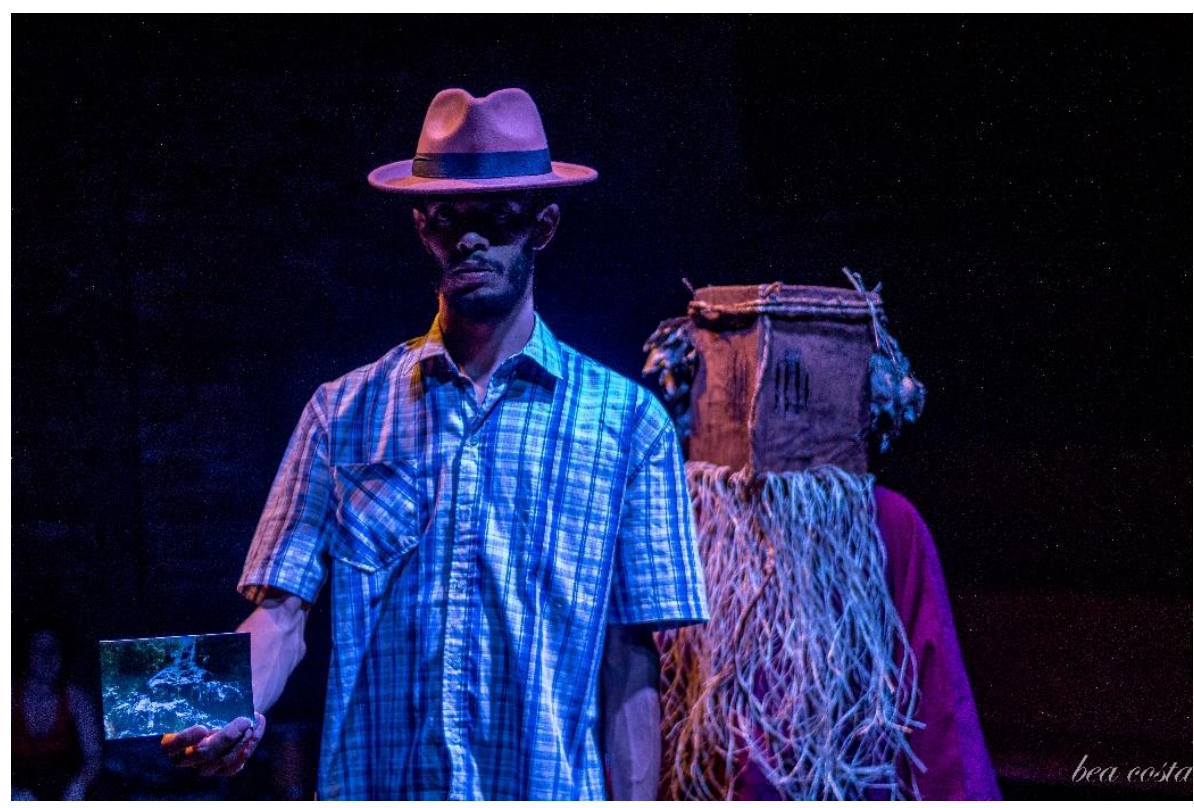

Fonte: Casa de Teatro Mariajosé de Carvalho - Dezembro/2017 - Foto: Bea Costa

\section{TERCEIRA TALHAGEM - EPISÓDIO III: BANZO E OS FILHOS DOS}

\section{ANTIGOS}

A terceira montagem da "Trilogia Vissungueira" avançou nas investigações da presença dos vissungos na formação cultural do povo brasileiro, a partir do choque das tradições Bantus diasporadas com as construções dos ideários escravagistas, eugenistas e miscigenatórios. 
Como orientação dramatúrgica este processo contou com a investigação da noção histórica, filosófica e psicológica do banzo - o estado de aguda melancolia sofrido pelos africanos escravizados na diáspora - como disparador para a criação artística, no sentido deste afeto poder ser o provocador da busca pelo sentimento de pertencimento na atualidade, a partir do movimento pelo encontro das experiências humanas que se plasmaram dentro dos cantos antigos para poder atravessar os tempos.

Neste aspecto se evidencia o alinhamento das propostas de diálogo que temos buscado entre as afro-epistemologias e as proposições conceituais e práticas de Jerzy Grotowski no tocante ao trabalho com ferramentais originários de tecnologias tradicionais.

Por exemplo, quem é a pessoa que está cantando a canção? É você? Mas se o som é de sua avó, é ainda você quem canta? (...) Talvez você vá mais atrás, em uma direção de tempo e espaço difícil de imaginar, quando alguém cantou esta música pela primeira vez. (...) Você tem a canção, você deve perguntar-se onde ela começou. (...) Quem era a pessoa que cantou assim? (...) Você, finalmente, descobre que você vem de algum lugar, ou como eles dizem, tradicionalmente, em uma velha expressão francesa, "Tu es le fils de quelqu'un" $\left.{ }^{[5}\right]$. Você não é um vagabundo, você vem de algum lugar, de algum país, de alguma paisagem. (...) Porque a pessoa que começou a cantar as primeiras palavras era filho de alguém, de algum lugar. (...) Este é um exemplo de como, começando com um elemento pequeno - uma canção - um grande número de problemas se descortinam. Todos os problemas humanos de tradição, raízes, fontes, a aparência da canção, o encantamento, todos os nossos relacionamentos humanos, nossa ancestralidade, através do tempo... tudo isto aparece. (Grotowski, 2009, p. 11-12, grifo nosso)

Algumas outras questões, próprias deste processo criativo, foram confrontadas: o quanto estaríamos sendo melancólicos ao buscar as pessoas presentes no interior destes cantos? Como eram estas pessoas? O que fariam conosco se reveladas? Assim, o ato de um atuante-cantante contemporâneo (e não necessariamente negro, ao menos em termos de fenótipo) ao realizar um canto tradicional e a sensação do banzo dos primeiros africanos no Brasil, contido nos vissungos, foram postos em atrito.

O banzo pode ser considerado como uma patologia que afetava os escravizados no Brasil, levando-os a comportamentos extremos: da euforia à violência, do suicídio ao assassinato. Mas também pode ser compreendido como um ato de protesto espontâneo contra o degredo, refletindo-se na forma de greves de fome, por exemplo. Cenicamente o recriamos como um estado de espírito que materializa uma África transtemporal, a âncora

15 "Você é filho de alguém." 
contra as ondas do não-lugar da diáspora forçada, um afeto provocador para a construção cênica de um diálogo com uma África simultaneamente ancestral e utópica.

Este espetáculo se utilizou, no seu processo criativo, de textos/documentos antigos e atuais sobre o banzo na perspectiva de mercadores e médicos, que imprimiram uma narrativa eurocêntrica deste fenômeno (como Luis Antonio de Oliveira Mendes), além de textos de abolicionistas-eugenistas e de sociólogos da miscigenação pacífica (como Joaquim Nabuco e Gilberto Freyre respectivamente). Tais textos foram contrapostos a textos/documentos afrocentrados de pesquisadores e escritores modernos que refletiram sobre este específico estado depressivo, em níveis filosóficos, sociopolíticos e artísticos (como Marcos Silva e Silva e Conceição Evaristo). Também se apoiou em textos dos próprios artistas-criadores, também em sua maioria negros (Bruna Carmo, Giovanna Monteiro, Hideo Kushiyama, Inessa Silva, Marcio Ribeiro, Priscila Roque e Rita Teles), em torno de questões como negritude e branquitude, tradição e progresso, legitimidade e apropriação cultural, criação de identidade afro-brasileira e miscigenação.

Figura 3: Cena de Episódio III: Banzo e os Filhos dos Antigos

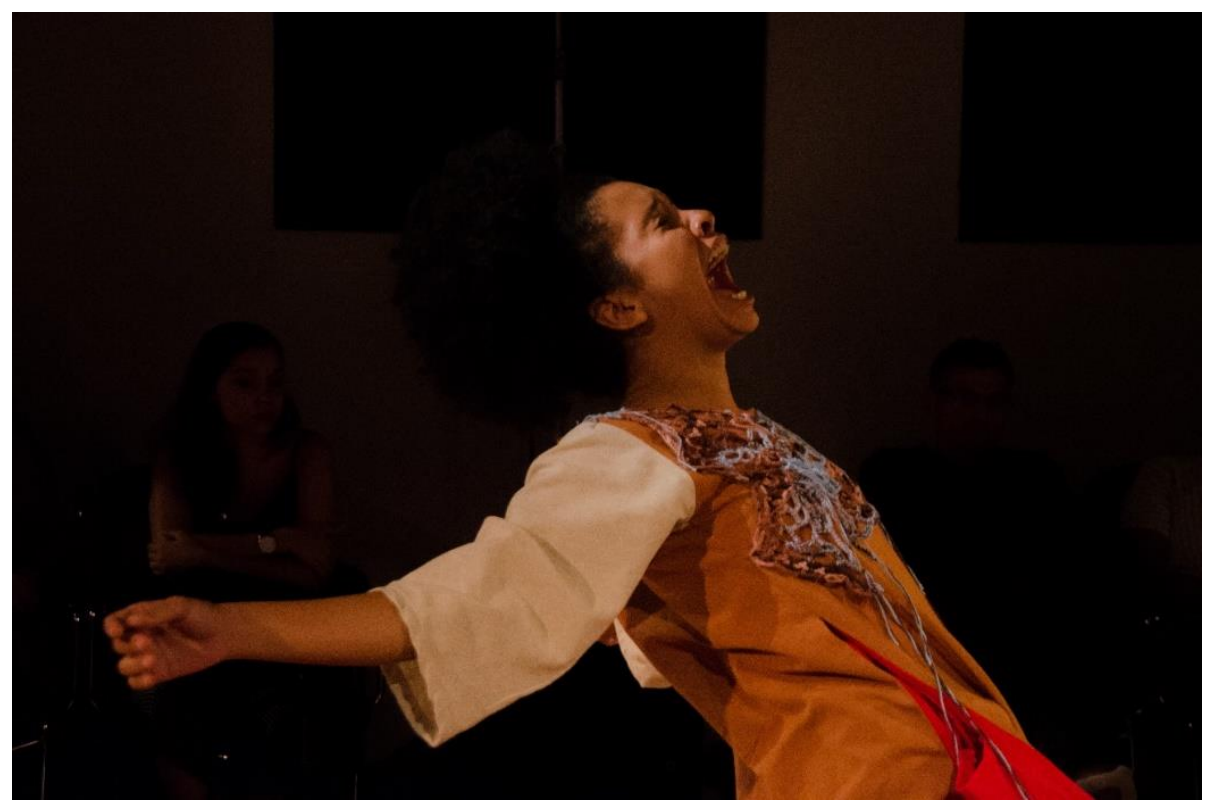

Fonte: Oficina Cultural Oswald de Andrade - Abril/2019 - Foto: Felipe Stucchi

EXPOSIÇÃO - SÍNTESE DO PROCESSO DE PESQUISA E CRIAÇÃO E A RECEPÇÃO DOS ESPECTADORES 
O cerne da criação destes três espetáculos foi a investigação, em cada artista que integrou cada projeto - e ainda tem integrado - do potencial de comportamento orgânico que um elemento de tradição, os vissungos, em franco desaparecimento, poderia trazer para a cena contemporânea. Em contraponto buscou simultaneamente compreender como a cena contemporânea colabora de maneira autêntica com a continuidade deste elemento de tradição, num outro tempo e num outro espaço, abrindo novos olhares (e escutas) sobre o sentido de preservação de um fundamento cultural afro-brasileiro de inestimável valor para a construção da identidade negra, tanto para o artista quanto para o público.

Também foi considerada, nestes processos criativos da "Trilogia Vissungueira", a importância da criação de situações de encontro dos espectadores-ouvintes com os cantos, com suas historicidades e mitopoéticas. Situações de escuta renovada ou inédita. Estas situações também visavam atingir o público não-negro, de modo que, ao confrontar questões como o racismo, afro-epistemicídio e branquitude, através das poéticas políticas inerentes às presenças físicas e simbólicas negras em cena, mediados pelos cantares de origem bantu, os trabalhos superavam a "ditadura da subjetividade" tanto criticada por Leda Maria Martins, alçando as discussões étnico-raciais para níveis estéticos complexos.

Considerando as variadíssimas formas de cultura tradicional afro-brasileira no país e o interesse constante de inúmeros grupos e artistas cênicos em trabalhar sobre essas fontes, a transmissão de novos referenciais de abordagem sobre este tipo de material, através da Plataforma Garimpar... tem real potencial de contribuição para o desenvolvimento das linguagens performativas brasileiras atuais, especialmente as que integram cena e música com base em elementos de tradição afrodescendente. Colaborando, assim, com a visão que foca a cultura popular e de matrizes ancestrais não como algo a ser reproduzido, transplantado para a cena na forma de um simpático folclore, mas algo a ser investigado em seus mecanismos geradores da potência viva da presença cênica, ou seja, em suas leis pragmáticas (Grotowski, 1991, p. 236). Ou seja, as tradições como fontes para se entender os meios que geram (ou geravam) a organicidade nos seus performers originais, a favor da movência dessas mesmas tradições e seus princípios em renovadas formas nas artes cênicas contemporâneas, bases sobre as quais o corpo e a poética de um determinado espetáculo podem ser construídos.

As diversas ações transversais criadas através da Plataforma Garimpar em Minas Negras Cantos de Diamante (oficinas, palestras, debates, intercâmbios), cujo centro 
foram - e são - os cantos que as geraram, formaram seus produtos principais, as obras teatrais, como um todo. Estas, antes de estrearem oficialmente, sempre passaram pela troca crítica com o público através de ensaios abertos e/ou aberturas de processo. Estes momentos foram de grande importância para as criações, pois neles foi possível ter o olhar cultivado de espectadores-artistas negros, que apontaram fragilidades a sanar e potências discursivas a investir nos processos de finalização das obras.

Os espetáculos criados pretenderam sensibilizar e estimular o interesse do público do século XXI, das mais amplas camadas sociais e intelectuais, sobretudo das novas gerações, afrodescendentes ou não, para a potência, qualidade artística e valor cultural dos vissungos para a construção da civilização brasileira, transmitindo um renovado "ponto-de-escuta-e-vista" da musicalidade e da palavra poética negra, instigando-os a acessarem por conta própria esta riquíssima herança dos povos Bantus. Cantos que são como elos perdidos fundamentais para se entender as origens da pessoa afrodescendente brasileira contemporânea e elemento central para o desenvolvimento de uma identidade afro-brasileira através de um veículo artístico.

Cantos que são conversas com as Áfricas sempre antigas, atuais e futuras.

\section{REFERÊNCIAS}

BROOK, Peter. Grotowski, el arte como vehículo. Máscara, ano 3, n. 11-12, 1993, p. 80-81. Ixtapalapa: Ed. Escenologia, A. C.

CARVALHO, José Jorge de. Um panorama da música afro-brasileira. In: FREITAS, Neide, Queiróz, Sônia. Vissungos: cantos afrodescendentes em Minas Gerais. $3^{\text {a }}$ ed. Belo Horizonte: Viva Voz, 2015.

FERREIRA, Tássio. Afrocênica: poéticas de cenas pretas. Revista da ABPN, v. 11, n. 27, nov. 2018 - fev. 2019, p.86-112.

GONÇALVES, A. L. Escravidão, herança ibérica e africana e as técnicas de mineração em Minas Gerais no século XVIII. In: Seminário sobre a economia mineira, 11., 2004. Diamantina. Anais... Belo Horizonte: CEDEPLAR/UFMG, 2004. p.1-23. Disponível em: <http://www.cedeplar.ufmg.br/diamantina2004/textos/D04A031.PDF>. Acesso em: 14 out. 2019.

GROTOWSKI, Jerzy. Da companhia teatral à arte como veículo. In: RICHARDS, Thomas. Trabalhar com Grotowski sobre as ações físicas. São Paulo : Perspectiva, 2012.

Leis pragmáticas. In: BARBA, Eugenio, SAVARESE, Nicola. A arte secreta do ator dicionário de antropologia teatral. São Paulo: Editora Hucitec, 1991. Tecniche originarie dell'attore. Roma : La Sapienza, 1987. Você é filho de alguém. REVISTA ENSAIO GERAL, Belém, v.1, n.1, jan-jun|2009. 
JAY, Martin. Cantos de experiencia: variaciones modernas sobre un tema universal. Buenos Aires : Paidós, 2009.

LIENHARD, Martin. O Mar e o Mato - Histórias da escravidão (Congo-Angola, Brasil, Caribe). Salvador : EDUFBA/CEAO, 1998.

LOPES, Nei. Novo dicionário Banto do Brasil. 2ª ed. Rio de Janeiro : Pallas, 2012.

MACHADO FILHO, Aires da Mata. O negro e o garimpo em Minas Gerais. Belo Horizonte : Ed. Itatiaia; São Paulo : Edusp, 1985.

ROCHA, Ivo Silvério da. Memórias de um catopê. Milho Verde/Serro : Sempre-viva editorial, 2015.

SAINT-HILAIRE, Auguste de. Viagem pelo distrito dos diamantes e pelo litoral do Brasil. Trad.: Leonan de Azeredo Pena. São Paulo, Rio de Janeiro, Recife, Porto Alegre: Companhia Editora Nacional, 1941. Acesso em 07/06/2019 <http://www.brasiliana.com.br/obras/viagem-pelodistrito-dos-diamantes-e-pelo-litoral-do-brasil/pagina/10/texto>

SANTO, Spírito. Na lapa de Makemba \#1. Acesso em 14/10/2019 < https://spiritosanto.wordpress.com/2009/01/18/na-lapa-de-makemba-parte-01/>

\section{REFERÊNCIAS FONOGRÁFICAS:}

AZEVEDO, Luís Heitor Corrêa. Music of Ceará and Minas Gerais. The Endangered Music Project. Washington : The Library of Congress, 1997. 